\title{
Intensity of Sole-source Light-emitting Diodes Affects Growth, Yield, and Quality of Brassicaceae Microgreens
}

\author{
Chase Jones-Baumgardt, David Llewellyn, Qinglu Ying, \\ and Youbin Zheng ${ }^{1}$ \\ School of Environmental Sciences, University of Guelph, 50 Stone Road East, \\ Guelph, ON, N1G 2W1, Canada
}

Additional index words. PPFD, TLI, controlled environment, kale, cabbage, arugula, mustard

\begin{abstract}
Indoor farming is an increasingly popular approach for growing leafy vegetables, and under this production system, artificial light provides the sole source (SS) of radiation for photosynthesis and light signaling. With newer horticultural lightemitting diodes (LEDs), growers have the ability to manipulate the lighting environment to achieve specific production goals. However, there is limited research on LED lighting specific to microgreen production, and available research shows that there is variability in how microgreens respond to their lighting environment. The present study examined the effects of SS light intensity (LI) on growth, yield, and quality of kale (Brassica napus L. 'Red Russian'), cabbage (Brassica oleracea L.), arugula (Eruca sativa L.), and mustard (Brassica juncea L. 'Ruby Streaks') microgreens grown in a walk-in growth chamber. SS LEDs were used to provide six target photosynthetic photon flux density density (PPFD) treatments: $100,200,300,400,500$, and $600 \mu \mathrm{mol} \cdot \mathrm{m}^{-2} \cdot \mathrm{s}^{-1}$ with a photon flux ratio of 15 blue: 85 red and a 16-hour photoperiod. As LI increased from 100 to $600 \mu \mathrm{mol} \cdot \mathrm{m}^{-2} \cdot \mathrm{s}^{-1}$, fresh weight $(\mathrm{FW})$ increased by $0.59 \mathrm{~kg} \cdot \mathrm{m}^{-2}(36 \%), 0.70 \mathrm{~kg} \cdot \mathrm{m}^{-2}(56 \%), 0.71 \mathrm{~kg} \cdot \mathrm{m}^{-2}$ $(76 \%)$, and $0.67 \mathrm{~kg} \cdot \mathrm{m}^{-2}(82 \%)$ for kale, cabbage, arugula, and mustard, respectively. Similarly, dry weight (DW) increased by $47 \mathrm{~g} \cdot \mathrm{m}^{-2}(65 \%), 45 \mathrm{~g} \cdot \mathrm{m}^{-2}(69 \%), 64 \mathrm{~g} \cdot \mathrm{m}^{-2}$ $(122 \%)$, and $65 \mathrm{~g} \cdot \mathrm{m}^{-2}(145 \%)$ for kale, cabbage, arugula, and mustard, respectively, as LI increased from 100 to $600 \mu \mathrm{mol} \cdot \mathrm{m}^{-2} \cdot \mathrm{s}^{-1}$. Increasing LI decreased hypocotyl length and hue angle linearly in all genotypes. Saturation of cabbage and mustard decreased linearly by $18 \%$ and $36 \%$, respectively, as LI increased from 100 to $600 \mu \mathrm{mol} \cdot \mathrm{m}^{-2} \cdot \mathrm{s}^{-1}$. Growers can use the results of this study to optimize SS LI for their production systems, genotypes, and production goals.
\end{abstract}

Microgreens are an emerging culinary trend due to their unique appearance and texture, intense flavors, and high nutrient densities (Xiao et al., 2012). Collectively, these crops are seedlings of vegetables and herbs, which are germinated and grown in lit environments and then harvested and consumed at an immature growth stage. Microgreens are densely seeded and harvested shortly after the cotyledons have fully developed, either with or without the emergence of the first true leaves depending on species. Harvesting is usually done 7 to $20 \mathrm{~d}$ after seeding, when they are 2.5 to $7.5 \mathrm{~cm}$ in height (Treadwell et al., 2016). Greenhouse and indoor growers have become interested in microgreen production due to increasing demand, short production cycles, and high market value, with wholesale prices ranging from $\$ 30$ to $\$ 50$ USD per pound (Treadwell

\footnotetext{
Received for publication 4 Dec. 2018. Accepted for publication 12 Apr. 2019.

We thank Natural Sciences and Engineering Research Council of Canada and Greenbelt Microgreens Ltd. for their financial support. We also thank Heliospectra AB (Gothenburg, Sweden) for providing LED lighting technologies for this study. ${ }^{1}$ Corresponding author. E-mail: yzheng@uoguelph. ca.
}

et al., 2016). The Brassicaceae family are especially popular to grow as microgreens because of their ease of germination, short growth cycles, varying colors, distinct flavors, and high phytochemical concentrations (Xiao et al., 2012)

Microgreens can be grown in myriad production scenarios, including outdoor, insoilless growing systems (Kyriacou et al., 2016). Indoor farming is an increasingly popular approach for growing leafy vegetables because it allows growers the greatest potential for manipulating the growing environment to optimize taste and morphology based on market preferences (Despommier, 2013) and produce highly uniform crops year round. Light is one of the most influential environmental factors on plant growth and morphology, especially in indoor farming where artificial lighting provides the SS of radiation for photosynthesis and light signaling. Historically, the most commonly used artificial light sources for controlled environment crop production have been fluorescent tubes in SS environments (Kozai, 2013) and high-intensity discharge lamps such as high-pressure sodium (HPS) in greenhouses (Ouzounis et al., 2015; Singh et al., 2015). Horticultural LEDs have become viable replacements for these older technologies bedoor, and greenhouse environments in soil or cause of their potential for high energy efficiency and durability, long lifetime, and low radiant heat emissions directed toward the crop (Mitchell and Stutte, 2017). It is also possible to adjust the intensity and spectrum with some horticultural LED systems (Llewellyn and Zheng, 2018), providing growers with additional tools with which they may be able to use light to manipulate crop growth, morphology, and phytochemical production (e.g., photoprotective pigments).

Although many studies have been conducted worldwide to investigate the use of LED technologies for growing myriad horticultural commodities in SS systems, there are still few robust studies related to the use of LEDs for the production of many important microgreens. The focus of the present study is on SS LED LI on yield and morphology of Brassicaceae microgreens. This study relates relevant crop production metrics to both instantaneous intensity of $P A R$, defined as the photosynthetic photon flux density $\left(P P F D, \mu \mathrm{mol} \cdot \mathrm{m}^{-2} \cdot \mathrm{s}^{-1}\right)$, and accumulated light over the complete production cycle, defined as total light integral (TLI, $\mathrm{mol} \cdot \mathrm{m}^{-2}$ ). An advantage of using TLI to quantify a crop's exposure to photosynthetic light is its potential to normalize yield results from different production scenarios (e.g., SS vs. greenhouse) and lighting environments (e.g., LI, photoperiod, and lengths of production cycles). Although TLI does not (yet) seem to be a commonly used metric in the scientific community, some greenhouse growers use light sums (typically from logged outdoor global radiation data) to assist with their production decisions, particularly regarding the use of supplemental lighting.

Several research groups have explored the relationships between SS LI and various growth and yield metrics of Brassicaceae microgreens. Samuoliene; et al. (2013) investigated the effects of five LED total photon flux density (TPFD, 400 to $800 \mathrm{~nm}$ ) levels ranging from 110 to $545 \mu \mathrm{mol} \cdot \mathrm{m}^{-2} \cdot \mathrm{s}^{-1}$ (16-h photoperiod) on growth and phytochemical content of four Brassicaceae genotypes: red pak choi, kohlrabi, tatsoi, and mustard. Their trial used modules comprising LEDs with peak wavelengths at 455,638 , 660 , and $735 \mathrm{~nm}$, respectively. They described the photon flux ratios (PFR) for their lighting treatments, but the PFR conflict with their referenced paper (Tamulaitis et al., 2005). Their PFR and TPFD levels were reportedly measured using a quantum sensor (RF-100, Sonopan, Poland) known to have varying wavelength sensitivity, meaning that PFR and absolute PPFD were likely inaccurate. Further, the authors did not describe plot-level uniformity distribution, it is unclear whether true statistical replication occurred, and neither FW nor DW data were reported, meaning readers cannot evaluate how LI affected crop yield (microgreen commodities are normally sold on a FW basis) or biomass (DW) metrics. Gerovac et al. (2016) reported on a factorial experiment that investigated three PFR and three 
TPFD levels $\left(105,210\right.$, and $\left.315 \mu \mathrm{mol} \cdot \mathrm{m}^{-2} \cdot \mathrm{s}^{-1}\right)$, all with a 16-h photoperiod, on the production of three Brassicaceae microgreen genotypes: kohlrabi, mizuna, and mustard. Their results showed FW increased up to $34 \%$ as LI increased from 105 to $315 \mu \mathrm{mol} \cdot \mathrm{m}^{-2} \cdot \mathrm{s}^{-1}$, depending on genotype and PFR. However, mustard only had LI treatment effects under two of the PFR and kohlrabi showed no LI treatment effects, regardless of PFR. It should be noted that FW was reported on a per-plant basis, which may not be a true reflection of LI treatment effects on yield. Because microgreens are typically grown as dense canopies [i.e., leaf area (LA) index $\geq 1$ ], yield data would be more appropriately represented on a per-unit-area basis (e.g., $\left.\mathrm{g} \cdot \mathrm{m}^{-2}\right)$. Gerovac et al. (2016) also reported an $\approx 25 \%$ increase in percent DW for kohlrabi and mustard as LI increased from 105 to $315 \mu \mathrm{mol} \cdot \mathrm{m}^{-2} \cdot \mathrm{s}^{-1}$, regardless of PFR. However, percent DW relates to plant water status (at harvest) and is not definitively indicative of crop yield. Moreover, because actual DW data were not presented, the relationships between LI and biomass production cannot be readily ascertained from this study. Both Samuoliené; et al. (2013) and Gerovac et al. (2016) found that hypocotyl length (HL) generally decreased with increasing LI, although results were not consistent across all LI $\times$ genotype combinations. Gerovac et al. (2016) speculated that the presence of far-red (FR, 700 to $800 \mathrm{~nm}$ ) in one of their PFR treatments could have induced shade avoidance responses characteristic of growing environments with low photon flux ratios of red (R, 600 to $700 \mathrm{~nm}$ ) to FR (R:FR) in some of the genotype $\times$ LI treatment combinations. However, shade avoidance responses are normally observed when plants are exposed to R:FR that are substantially lower than parity (Blom et al., 1995; Fletcher et al., 2005; Mah et al., 2018). Therefore, a shade avoidance response was highly unlikely in this growing environment, particularly because the shoot apical meristem of individual plants would not have been subject to substantial amounts of vegetated shade. Although theirs was not a microgreens study, Potter et al. (1999) reported responses of canola (Brassica napus L. 'Westar') seedlings to SS PPFD ranging from 25 to 500 $\mu \mathrm{mol} \cdot \mathrm{m}^{-2} \cdot \mathrm{s}^{-1}$. The seedlings were grown on a per-cell basis in a germination tray (vs. a dense microgreen canopy), but the responses of height and biomass metrics are nevertheless revelatory as to how Brassicaceae microgreens respond to increasing LI. They found $\approx 2$-fold reductions in height and increase in aboveground biomass, respectively, as LI increased from 150 to $500 \mu \mathrm{mol} \cdot \mathrm{m}^{-2} \cdot \mathrm{s}^{-1}$, when harvested 16 to $17 \mathrm{~d}$ after sowing. They attributed the decreases in HL at higher LI to decade-level decreases in concentrations of endogenous gibberellins.

In SS production environments, the use of higher LI to increase crop yields and quality must be balanced against the higher input costs of lighting infrastructure and energy, to maximize profit. From the aforementioned studies, there clearly exists a need for further clarity on how Brassicaceae microgreens respond to LED LI in SS production environments, particularly regarding economically relevant production metrics such as HL and fresh and dry yield per unit area. The objectives of this study were to investigate the influence of SS LED $\mathrm{LI}$, ranging from 100 to $600 \mu \mathrm{mol} \cdot \mathrm{m}^{-2} \cdot \mathrm{s}^{-1}$ (with a 16-h photoperiod) on growth, yield, and quality of commercially relevant Brassicaceae microgreens and develop mathematical models to describe these relationships.

\section{Materials and Methods}

Growing media and seeding. Seedlings of kale (Brassica napus L. 'Red Russian'), cabbage (Brassica oleracea L.), arugula (Eruca sativa L.), and mustard (Brassica juncea L. 'Ruby Streaks') were grown in fiber trays $(23.5 \times 48.5 \times 3.5 \mathrm{~cm})$ for 10 to $11 \mathrm{~d}$ after sowing. The growing substrate comprised (by volume) $30 \%$ peat, $30 \%$ compost, $30 \%$ coir, and $10 \%$ perlite. The substrate analysis indicated that the macronutrient concentrations $\left(\mathrm{mg} \cdot \mathrm{kg}^{-1} \mathrm{DW}\right)$ were $1410 \mathrm{~K}, 1390 \mathrm{Ca}, 329 \mathrm{P}, 295 \mathrm{Mg}, 220 \mathrm{~S}$, and $42 \mathrm{~N}-\mathrm{NO}_{3}$; the micronutrient concentrations (mg. $\mathrm{kg}^{-1} \mathrm{DW}$ ) were $218 \mathrm{Na}, 47 \mathrm{Fe}, 10 \mathrm{Mn}$, 9.4 Zn, $0.7 \mathrm{~B}$, and $0.6 \mathrm{Cu}$. Trays were machine-filled with substrate and preseeded at Greenbelt Microgreens (Lynden, Ontario, Canada) on the day each replication was started. Seeding rates were the same as used in production at Greenbelt Microgreens. Pertray seeding rates, which varied according to seed size, were $8 \mathrm{~g}$ for kale $(2.78 \mathrm{mg} / \mathrm{seed})$, $10 \mathrm{~g}$ for cabbage $(2.84 \mathrm{mg} / \mathrm{seed})$, and $4 \mathrm{~g}$ for arugula $(1.56 \mathrm{mg} / \mathrm{seed})$, and mustard (1.63 $\mathrm{mg} / \mathrm{seed}$ ), resulting in seeding densities ranging from 2.15 to 3.09 seeds $/ \mathrm{cm}^{2}$. Trays of microgreens were top-irrigated with well water as needed.
Growth chamber environment. The experiment was conducted at the University of Guelph (Ontario, Canada), with sequential replications starting on 13 Oct., 14 Nov., and 12 Dec. 2017, respectively. A $29 \mathrm{~m}^{2}$ walk-in growth chamber was divided into six $1.5-\mathrm{m}^{2}$ treatment plots, surrounded by opaque white vertical blinds to prevent light contamination between treatments, while still allowing sufficient airflow to maintain uniform temperature and humidity throughout the growth chamber. Each plot was divided into four subplots that were the same dimensions as a single tray. The four species were each randomly assigned to one of the subplots within each plot. Tray positions rotated clockwise daily, while maintaining a constant aspect, to enhance uniformity of crops' exposure to light. The growing area for each light treatment was $0.46 \mathrm{~m}^{2}$ and was centered directly below the lights.

Lighting Setup. LED arrays (LX601C, Heliospectra AB, Gothenburg, Sweden) were used to provide six $P P F D$ treatments: 100, 200, 300, 400, 500, and $600 \mu \mathrm{mol} \cdot \mathrm{m}^{-2} \cdot \mathrm{s}^{-1}$ (Table 1), measured at the level of the top of the substrate. These fixtures have four separately controllable spectrum channels: B (peak $445 \mathrm{~nm}$ ), R (peak $660 \mathrm{~nm}$ ), white (W, $5700 \mathrm{~K}$ broad spectrum), and FR (peak 735 $\mathrm{nm})$. Only the B and R channels were used in the present study, with the fixtures configured to provide a photon flux ratio of B15:R85. For each treatment, two LED arrays, spaced 36 $\mathrm{cm}$ apart (on center, with the long sides of the fixtures parallel), were mounted $56.5 \mathrm{~cm}$ above the top of the substrate (measured from the bottom of the LED array). For the 600 $\mu \mathrm{mol} \cdot \mathrm{m}^{-2} \cdot \mathrm{s}^{-1}$ treatment, a third fixture was centered between the other two at the same elevation and aspect, which resulted in $1-\mathrm{cm}$ gaps between the near sides of adjacent fixtures. LI and spectral quality were

Table 1. Mean photosynthetic photon flux density $(P P F D)$ from red (R) and blue (B) light (and combined) delivered from sole-source LEDs to achieve a target light ratio $(\%)$ of red to blue 85:15 $\left(\mathrm{R}_{85}: \mathrm{B}_{15}\right)$ with target $P P F D$ levels of $100,200,300,400,500$, and $600 \mu \mathrm{mol} \cdot \mathrm{m}^{-2} \cdot \mathrm{s}^{-1}$. Mean values reported are the average of 25 spectral scans before each respective replicate.

\begin{tabular}{lcccr}
\hline \multicolumn{5}{c}{$P P F D\left(\mu \mathrm{mol} \cdot \mathrm{m}^{-2} \cdot \mathrm{s}^{-1}\right)$} \\
\hline Target $^{z}$ & Blue $(400-500 \mathrm{~nm})$ & $\operatorname{Red}(600-700 \mathrm{~nm})$ & Total & DLI $^{\mathrm{y}}$ \\
\hline 100 & $15.1 \pm 0.8^{\mathrm{Y}}$ & $83.5 \pm 4.1$ & $98.6 \pm 4.9$ & 5.8 \\
& $15.4 \pm 0.8$ & $85.1 \pm 4.5$ & $101 \pm 5.2$ & \\
200 & $14.7 \pm 1.0$ & $82.7 \pm 5.2$ & $97.4 \pm 6.1$ & \\
& $30.4 \pm 2.0$ & $169 \pm 10.6$ & $199 \pm 12.6$ & 11.5 \\
300 & $30.5 \pm 1.7$ & $173 \pm 9.9$ & $204 \pm 11.6$ & \\
& $31.1 \pm 1.3$ & $174 \pm 7.7$ & $205 \pm 9.0$ & 17.3 \\
400 & $45.2 \pm 2.5$ & $255 \pm 3.0$ & $300 \pm 5.5$ & \\
& $45.7 \pm 2.9$ & $259 \pm 16.3$ & $304 \pm 19.2$ & \\
500 & $46.0 \pm 3.0$ & $259 \pm 18.0$ & $305 \pm 20.9$ & \\
& $60.5 \pm 3.6$ & $340 \pm 18.8$ & $401 \pm 22.4$ & 23.0 \\
600 & $59.6 \pm 4.6$ & $337 \pm 23.7$ & $397 \pm 28.2$ & \\
& $60.5 \pm 3.2$ & $344 \pm 17.1$ & $404 \pm 20.2$ & \\
& $74.3 \pm 5.2$ & $427 \pm 27.3$ & $501 \pm 24.2$ & 28.9 \\
& $75.1 \pm 4.9$ & $423 \pm 25.1$ & $498 \pm 30.0$ & \\
& $75.3 \pm 4.2$ & $431 \pm 22.6$ & $506 \pm 26.8$ & 34.6 \\
\hline
\end{tabular}

${ }^{\mathrm{z}}$ The three rows within each target $P P F D$ level represent $P P F D$ means \pm sD for the respective treatments $(\mathrm{n}=25)$ for replicate 1,2 , and, 3 , respectively.

${ }^{\mathrm{y}} \mathrm{DLI}=$ daily light integral $\left(\mathrm{mol} \cdot \mathrm{m}^{-2} \cdot \mathrm{d}^{-1}\right)$. 
measured using a radiometrically calibrated ultraviolet-VIS Flame spectrometer (Ocean Optics, Dunedin, FL) coupled to a $400 \mathrm{~nm} \times$ $1.9 \mathrm{~m}$ patch cord with a CC 3 cosine corrector and tethered to a laptop running the Spectrasuite software package. Spectral power distribution was converted to photon flux using the PARspec subroutine. Before commencing each replicate, LI and B:R were measured in 25 locations in each plot, on a $16.7 \times 16.7 \mathrm{~cm}$ square grid, centered under the LED arrays (Table 1). Intensity and uniformity measurements were repeated after harvest to confirm that the average $P P F D$ of $\mathrm{B}: \mathrm{R}$ did not change more than $\pm 3 \%$, within each plot, over the course of each respective replicate.

The LED arrays and growth chamber environmental control were set to the same daily 16-h light (L)/8-h dark (D) photoperiod with $\mathrm{L} / \mathrm{D}$ temperature setpoints of $21{ }^{\circ} \mathrm{C} /$ $17{ }^{\circ} \mathrm{C}$ and a constant $80 \%$ relative humidity (RH) setpoint. Three data loggers (HOBO U12-013; Onset Computer Corporation, Bourne, MA) were used to record air temperature and RH every 120 s. For each replicate, the loggers were positioned on the bench adjacent to the microgreen trays in three randomly selected plots. Halfway through each trial, the logger locations were switched to the other three plots to provide plot-level environmental data for each plot for half of the duration of each replication. This resulted in 18 unique data-collection events that, when the means for each event were averaged, resulted in $\mathrm{L} / \mathrm{D}$ temperatures and $\mathrm{RH}$ (mean $\pm \mathrm{SD}$ ), of $21 \pm 0.42{ }^{\circ} \mathrm{C} / 17 \pm$ $0.31{ }^{\circ} \mathrm{C}$ and $\mathrm{RH}$ of $86 \pm 1.9 \%$. Supplemental $\mathrm{CO}_{2}$ was not used in the experiment, and the mean chamber $\mathrm{CO}_{2}$ concentration (mean \pm $\mathrm{SD}$ ) during the daylight period was $470 \pm 22$ ppm.

Growth and morphology measurements. Growth and morphology measurements were taken $10 \mathrm{~d}$ after sowing for kale and cabbage and $11 \mathrm{~d}$ after sowing for arugula and mustard. Five representative plants from each subplot were selected to determine HL, which was measured from the base of the hypocotyl to the shoot apical meristem using a ruler. Three subsamples, each comprising five representative plants from the remaining plants in each subplot, were collected to measure LA using an LA meter (LI-3100C; LI-COR Biosciences, Lincoln, NE). If visible, true leaves were of insignificant size, and therefore only cotyledons were used for LA measurements. Three additional representative samples (i.e., full plants and substrate) were collected using a cylindrical core sampler $\left(76.4 \mathrm{~cm}^{2}\right)$ from each subplot to measure fresh and dry yield. All plants within each core were cut just above substrate level and combined to determine FW. Each sample was dried in an oven at $70{ }^{\circ} \mathrm{C}$ for $3 \mathrm{~d}$ to constant weight, and DWs were recorded.

Digital image analysis of cotyledons. Five representative cotyledons (one per plant from five plants) per subplot were scanned (CanoScan LiDE 25; Canon Inc., Tokyo, Japan) in JPEG format at 297 pixels per inch. ImageJ
1.42 software (https://imagej.nih.gov/ij/ download.html) was used to determine red, green, and blue (RGB) values for each image, which were then converted into hue and saturation values using the formulas outlined by Karcher and Richardson (2003). Hue angle (HA) refers to a position on a continuous circular scale $\left(0^{\circ}\right.$ to $\left.360^{\circ}\right)$, and saturation refers to the purity of a color with $0 \%$ and $100 \%$ representing gray and full saturation, respectively (Karcher and Richardson, 2003). A calibration curve was obtained by fitting a linear regression equation to $\mathrm{HA}$ values measured by scanning 12 color chips from the Munsell Color Charts for Plant Tissues (GretagMacbeth LLC, New Windsor, NY) with varying HAs, ranging from green to red (5Y 6/6, 2.5GY 6/6, 5GY 6/6, 7.5GY 6/6, $2.5 \mathrm{G} 6 / 6,5 \mathrm{G} 6 / 6,5 \mathrm{Y} 6 / 6,2.5 \mathrm{GY} 6 / 6,5 \mathrm{GY}$ $6 / 6,7.5 \mathrm{GY} 6 / 6,2.5 \mathrm{G} 6 / 6$, and $5 \mathrm{G} 6 / 6$ ). The present study's HA values were corrected based on the resulting linear regression equation: $\mathrm{y}=0.993 \mathrm{x}+10.7\left(r^{2}=0.996\right)$ where $\mathrm{y}=$ actual HA of Munsell Color Chart for Plant Tissues color chips and $\mathrm{x}=$ HA quantified by digital image analysis.

Statistical analysis. The experiment was a randomized complete block design with six LI treatments, four microgreen genotypes, and three consecutive replications. Data were analyzed using R statistical software (RStudio 1.1.453; Auckland, New Zealand). HL, LA, HA, and saturation were individually analyzed using linear regressions, and FW and DW were individually analyzed using asymptotic light response curves (described subsequently), with both the independent (i.e., PPFD and TLI) and dependent (i.e., production and harvest indices) values as continuous variables. The relationships between LI and yield (FW or DW) were determined using the asymptotic model $\mathrm{y}=\mathrm{a}+$ $\mathrm{b} e^{(\mathrm{cx})}$ (Delgado et al., 1993), where $\mathrm{y}, \mathrm{x}, \mathrm{a}$, and $e$ represent yield, LI (i.e., PPFD or TLI), estimated maximum yield, and Euler's number, respectively. The parameters for $a, b$, and $\mathrm{c}$ were derived through nonlinear regressions. All regression analyses were evaluated at $P \leq 0.05$ level of statistical significance. The best-fit model regressions and equations are only presented for production and harvest indices with significant regressions. Normality of residuals and homoscedascity of variances were confirmed by using the Shapiro-Wilk and Levene test, respectively.

\section{Results}

Results are discussed primarily in terms of $P P F D$ to be most relatable to similar studies. However, because PPFD and TLI are proportional in this study (because LI and photoperiod are fixed levels), the models are also presented in terms of TLI (Fig. 1) and the respective models share a common $r^{2}$. Also note that the growing period for arugula and mustard was $1 \mathrm{~d}(\approx 9 \%)$ longer than cabbage and kale. Therefore, while the PPFD levels (on the $\mathrm{x}$-axes) are the same for all genotypes, the TLI for cabbage and kale are smaller than for arugula and mustard. Therefore, when considered on a $P P F D$-basis, the timeweighted effects of LI on harvest metrics may be more pronounced between some genotypes than the harvest data indicates.

As LI increased from 100 to 600 $\mu \mathrm{mol} \cdot \mathrm{m}^{-2} \cdot \mathrm{s}^{-1}$, HL decreased linearly by 1.5 $\mathrm{cm}(24 \%), 0.80 \mathrm{~cm}(23 \%), 1.1 \mathrm{~cm}(37 \%)$, and $2.3 \mathrm{~cm}(62 \%)$ for kale, cabbage, arugula, and mustard, respectively (Fig. 1A-D). There were no treatment effects on per-plant LA (Fig. 1E-H). Both FW and DW increased asymptotically as LI increased. As LI increased from 100 to $600 \mu \mathrm{mol} \cdot \mathrm{m}^{-2} \cdot \mathrm{s}^{-1}$, FW increased by $0.59 \mathrm{~kg} \cdot \mathrm{m}^{-2}(36 \%), 0.70 \mathrm{~kg} \cdot \mathrm{m}^{-2}$ $(56 \%), 0.71 \mathrm{~kg} \cdot \mathrm{m}^{-2}(76 \%)$, and $0.67 \mathrm{~kg} \cdot \mathrm{m}^{-2}$ $(82 \%)$ for kale, cabbage, arugula, and mustard, respectively (Fig. 1I-L). As LI increased from 100 to $600 \mu \mathrm{mol} \cdot \mathrm{m}^{-2} \cdot \mathrm{s}^{-1}$, DW increased by $47 \mathrm{~g} \cdot \mathrm{m}^{-2}(65 \%), 45 \mathrm{~g} \cdot \mathrm{m}^{-2}(69 \%)$, $64 \mathrm{~g} \cdot \mathrm{m}^{-2}(122 \%)$, and $65 \mathrm{~g} \cdot \mathrm{m}^{-2}(145 \%)$ for kale, cabbage, arugula, and mustard, respectively (Fig. 1M-P). As LI increased from 100 to $600 \mu \mathrm{mol} \cdot \mathrm{m}^{-2} \cdot \mathrm{s}^{-1}$, HA decreased by 35,19 , 19 , and $25^{\circ}$ for kale, cabbage, arugula, and mustard, respectively (Fig. 1Q-T). Saturation of kale and arugula was not influenced by LI (Fig. 1U and W); however, saturation of cabbage and mustard increased by $18 \%$ and $36 \%$, respectively, as LI increased from 100 to $600 \mu \mathrm{mol} \cdot \mathrm{m}^{-2} \cdot \mathrm{s}^{-1}$ (Fig. $1 \mathrm{~V}$ and $\mathrm{X}$ ).

\section{Discussion}

From a production standpoint, microgreens represent a unique commodity in that the input biomass (i.e., the seeds) and the harvested crop (i.e., aboveground biomass of young plant at or before the first true leaf stage) may not be that different. Unlike more mature plant life forms, embryos of germinating seeds rely solely on stored energy resources before the development and activation of the photosynthetic machinery. The transition from heterotrophic to autotrophic growth is a dynamic process that is influenced by myriad factors, such as seed size, planting depth, temperature, and availability of PAR. Although there were no direct measurements made on photosynthesis or the balance of autotrophic vs. heterotrophic growth in this study, the modeled relationships between LI and harvest metrics (Fig. 1) clearly show the autotrophic proclivity of the crops by the time of harvest.

Increasing LI is commonly associated with more compact growth (i.e., shorter internodes) in mature vegetative plant tissues (Burkholder, 1936; Butler, 1963; Yeh and Hsu, 2004; Zervoudakis et al., 2012), but the influence of LI on HL of young seedlings has not been as well documented. Some studies on seedlings of floriculture and vegetable crops have presented mixed results on the effects of LI on HL (Craver et al., 2018, 2019; Hernández and Kubota, 2014; Poel and Runkle, 2017; Pramuk and Runkle, 2005; Randall and Lopez, 2015), usually with either reductions or no change in HL with increasing LI. Seedlings of Brassica genotypes all tend to grow shorter under higher LI (Gerovac et al., 2016; Potter et al., 1999; Samuoliené; 


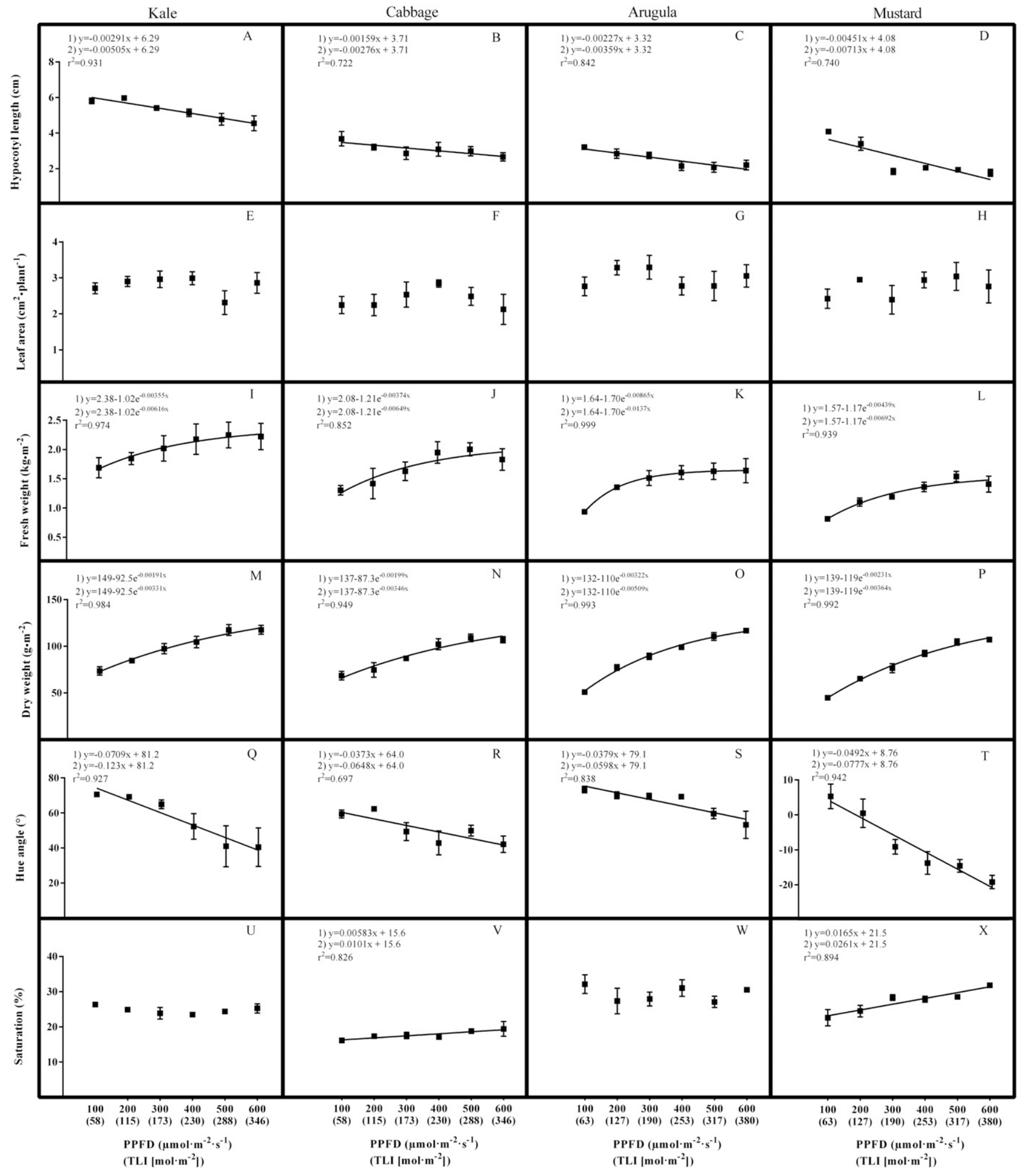

Fig. 1. Hypocotyl length (A-D), leaf area (E-H), fresh weight (I-L), dry weight (M-P), hue angle (Q-T), and saturation (U-X) of kale (Brassica napus L. 'Red Russian'), cabbage (Brassica oleracea L.), arugula (Eruca sativa L.), and mustard (Brassica juncea L. 'Ruby Streaks') microgreens grown under photosynthetic photon flux density (PPFD) levels of $100,200,300,400,500$, and $600 \mu \mathrm{mol} \cdot \mathrm{m}^{-2} \cdot \mathrm{s}^{-1}$ delivered from sole-source LEDs with a blue (B) to red (R) photon flux ratio of B15:R85. Data and models are also presented in terms of total light integral (TLI, mol $\cdot \mathrm{m}^{-2}$ ), which is the integral of $P P F D$, photoperiod, and days of production. All regression analyses were evaluated at $P \leq 0.05$ level of statistical significance. The best-fit model regressions and equations are only presented for production and harvest indices with significant regressions. Error bars indicate $\pm \mathrm{SE}(\mathrm{n}=3)$.

et al., 2013), although the magnitude of the effects may be influenced by genotype, seed size, seeding density, and time between sowing and harvest. When harvested between HortSCIENCE Vol. 54(7) July 2019
10 and $15 \mathrm{~d}$ after sowing (DAS), Gerovac et al. (2016) reported reductions in HL of up to $30 \%$ in kohlrabi, mizuna, and mustard microgreens (seeding rate between 12 and 20 $\mathrm{mg} \cdot \mathrm{cm}^{-2}$ ) as LI increased from 105 to 315 $\mu \mathrm{mol} \cdot \mathrm{m}^{-2} \cdot \mathrm{s}^{-1}$, under most genotype-by-PFR combinations. Samuoliené; et al. (2013) reported reductions in HL ranging between $9 \%$ 
and $28 \%$ in 10 -d-old mustard, red pak choi, tatsoi, and kohlrabi microgreens (sown at between 5 and $10 \mathrm{mg} \cdot \mathrm{cm}^{-2}$ ) when grown at $545 \mathrm{vs} .110 \mu \mathrm{mol} \cdot \mathrm{m}^{-2} \cdot \mathrm{s}^{-1}$. In contrast to these studies, Potter et al. (1999) showed $\approx 3$-fold shorter HL, both 7 and 14 DAS, in canola (Brassica napus L. 'Westar') seedlings grown (one seedling per cell) at 500 vs. 150 $\mu \mathrm{mol} \cdot \mathrm{m}^{-2} \cdot \mathrm{s}^{-1}$. Given these varying responses of similar genotypes to LI under different planting densities, plant responses to vegetated shade may be antagonistic to the full phenotypic expression of LI-induced reductions in HL, such as in the production of endogenous gibberellins (Potter et al., 1999). The differences between genotypes in their LI effects on HL may have also been influenced by the availability of stored energy resources (i.e., size of seed). To illustrate this, kale and cabbage, the two tallest genotypes (for a given LI) in the present study, had about twice the seed size and also had higher seeding densities than arugula and mustard. High LI-mediated reductions in HL may have important ramifications for microgreen production as shorter HL may increase overall crop robustness and lengthen postharvest shelf life; however, shorter HL can also increase difficulty of harvesting, particularly if harvesting is done by machine. Depending on the importance of $\mathrm{HL}$ at harvest, relative to other production metrics (e.g., yield), it may be possible to counteract the LI-induced reductions in HL by using targeted light spectrum treatments such as a reduced photon flux ratio of $\mathrm{R}$ to FR light (Blom et al., 1995; Fletcher et al., 2005; Hisamatsu et al., 2008; Mah et al., 2018) or monochromatic blue light treatments (Hata et al., 2013; Hernández and Kubota, 2016; Kim et al., 2014; Kong et al., 2018) to stretch the plants.

Probably the most important harvest metric for commercial microgreen production is fresh yield (i.e., $\mathrm{kg}_{(\mathrm{FW})} \cdot \mathrm{m}^{-2}$ ) because microgreens are typically sold on a "per-FW" basis. All genotypes in the present study showed asymptotic trends of increasing FW with increasing LI. Kale and cabbage had higher yield at a given LI than arugula and mustard, which may have been partly due their higher seed sizes and seeding densities. The FW data (on a per-plant basis) reported by Gerovac et al. (2016) only showed treatment effects on some genotype $\times$ PFR combinations, with no LI treatment effects in kohlrabi or mizuna regardless of PFR and $19 \%$ and $34 \%$ increase in FW in mustard for the PFRs with $7 \%$ FR and $18 \%$ green $(\mathrm{G}, 500$ to $600 \mathrm{~nm}$ ), respectively, as LI increased from 105 to $315 \mu \mathrm{mol} \cdot \mathrm{m}^{-2} \cdot \mathrm{s}^{-1}$. Their $\mathrm{FW}$ results for mizuna are conflicting between their text $(15 \%$ increase in FW regardless of PFR) and graphical results (no difference in FW), as LI increased from 105 to 315 $\mu \mathrm{mol} \cdot \mathrm{m}^{-2} \cdot \mathrm{s}^{-1}$. On the basis of the asymptotic models of FW response to LI in the present study, the crops in Gerovac et al. (2016) should have been well below the saturation point on their respective light response curves, and thus readily responded to increasing LI with increasing biomass produc- tion. However, it is still not readily apparent how increasing LI by a factor of 3 (i.e., increasing DLI from 6 to $18 \mathrm{~mol} \cdot \mathrm{m}^{-2} \cdot \mathrm{d}^{-1}$ ) did not have substantial LI treatment effects on fresh yield for many genotype $\times$ PFR combinations in the Gerovac et al. (2016) study. This may indicate that other (unknown) factors related to growing environment or crop husbandry may have been limiting plant growth and yield in their experiments. Notably, kohlrabi, which was the genotype that showed the lowest FW response to increasing LI, also had the largest seeds (i.e., $\approx 2$-fold higher mass per seed than mizuna and mustard) based on current information from their seed supplier (Johnny's Selected Seeds, Winslow, ME). Regrettably, the Samuoliené; et al. (2013) paper did not present any FW data for their crops. Both Gerovac et al. (2016) and Samuoliene; et al. (2013) presented "percent DW" data, but this metric is essentially a measure of water content at the time of harvest and does not relate directly to biomass production. The trend of increasing percent DW (i.e., decreasing water content) with increasing LI in the present study (data not directly shown) are similar to the trends reported by both Gerovac et al. (2016) and Samuoliené; et al. (2013). These observations may be indicative of inherently reduced water content in plants grown under higher LI or may be an artifact of inadequate irrigation strategies in some studies, perhaps related to disparate water demand of plants grown under large LI ranges.

DW yield data, although less directly applicable to commercial production goals than FW, is the most widely used metric in academia for assessing treatment effects on biomass accumulation, particularly in foliar tissues. In the present study, DW followed similar trends as FW. Overall, a 6-fold increase in LI resulted in a 1.6- to 2.5 -fold increase in (aboveground) DW production. When an asymptotic model was applied to the aboveground DW data presented in Potter et al. (1999), there was an $\approx 3$-fold increase in canola yield over the same range of LI (model extrapolated to $600 \mu \mathrm{mol} \cdot \mathrm{m}^{-2} \cdot \mathrm{s}^{-1}$ ). However, because their plants were harvested 17 DAS, the TLI was more than $35 \%$ higher than the TLI in the present study (for a given $P P F D$ ); therefore, over a comparable TLI the increase in aboveground DW would be closer to 2fold. This comparison exemplifies why extreme caution is required when relating results of different LI trials on the basis of $P P F D$ or (to a lesser extent) DLI. Further, although it has been said that $1 \%$ more light should result in concomitant $0.5 \%$ to $1 \%$ increases in crop yields (Marcelis et al., 2006), this generalization appears to be exaggerated for microgreen production, where growing cycles are short and seed storage likely provides a disproportionate contribution to the total harvest biomass. The net gains in DW were $47.0 \mathrm{~g} \cdot \mathrm{m}^{-2}, 45.1 \mathrm{~g} \cdot \mathrm{m}^{-2}$, $63.7 \mathrm{~g} \cdot \mathrm{m}^{-2}$, and $64.7 \mathrm{~g} \cdot \mathrm{m}^{-2}$ for kale, cabbage, arugula, and mustard, respectively, as LI increased from 100 to $600 \mu \mathrm{mol} \cdot \mathrm{m}^{-2} \cdot \mathrm{s}^{-1}$.
When considering these gains in DW along with the initial seed (input) mass of the different genotypes, it would appear that seedlings of smaller-seeded genotypes, such as arugula and mustard, may have considerably higher phenotypic plasticity for biomass accumulation responses to increasing LI, even when accounting for their higher DAS (i.e., higher TLI). This may be an important consideration for growers to balance when considering the various input costs associated with the two main drivers of harvestable biomass accumulation in microgreen production: initial seed resources and photosynthetic light inputs.

While there were increasing trends for aboveground fresh and dry biomass metrics with increasing LI, there were no LI treatment effects on leaf area for any of the genotypes. Although the relative biomass allocation to hypocotyl and leaf tissues were not assessed in this study, it is likely that higher LI treatments produced plants with greater leaf thickness because this trend has been observed in other species and production scenarios (Givnish et al., 2004; Matos et al., 2009; Morais et al., 2004; Sims and Pearcy, 1994). Further, because tissue water potential and morphological factors that can influence the rate of postharvest water loss may also have a substantial influence on shelf life, more research is needed to elucidate how varying LI affects leaf morphology (particularly leaf thickness and stomatal densities) and relate these metrics to shelf life.

The general decreases in HA observed in the cotyledons of all genotypes were indicative of increases in the proportions of yellow and red pigments in the cotyledons of kale, cabbage, and arugula (all green colored plants), and purple (likely associated with anthocyanins) in the cotyledons of mustard (reddish-purple colored). Only mustard cotyledons had LI treatment effects on saturation (i.e., purity of color relative to gray), with increasing saturation at higher LI. These observations may be indicative of increased concentrations of carotenoids and anthocyanins at higher LI. Carotenoids in the chloroplast play an essential photoprotective role in reducing photooxidative damage to the photosynthetic apparatus caused by excess LI (Krinsky, 1979). Chloroplast-specific carotenoids are synthesized in response to light to protect against photoinhibition (Bou-Torrent et al., 2015; Llorente et al., 2017; ToledoOrtiz et al., 2010). Anthocyanins have also been shown to screen photosynthetic tissues from high light intensities (Smillie and Hetherington, 1999), and increased anthocyanin synthesis has been shown to occur under high LI (Krol et al., 1995; Mancinelli, 1983). It is also likely that higher LI reduced the quality of the visual appearance of Brassicaceae microgreens, although how the magnitude of these differences relates to normal human perception of plant color was beyond the scope of this study. Because plant color is the most important visual indicator of plant quality and health (Barrett et al., 2010), it is possible that deleterious effects of higher LI 
on the visual appearance of Brassicaceae microgreens may somewhat offset any increases in yield.

Overall, the magnitude of the morphological and yield responses expressed by the four genotypes indicated that arugula and mustard exhibited greater levels of phenotypic plasticity to LI than kale and cabbage. This may have important production implications as growers may wish to assign different levels of lighting infrastructure and energy budget to growing commodities that exhibit greater yield responses to increasing LI. Photoperiod and spectrum were kept at fixed levels, with varying $P P F D$ levels in the present study. Lighting at lower intensities for longer photoperiods (up to and including continuous lighting) and gradually increasing the LI as the crop matures (either using dimmers or by moving the plants between zones with different LI) are other common methods for reducing costs associated with crop lighting. In some cases, crops are even kept in the dark until germination is complete and the cotyledons have unfolded. These additional strategies also deserve attention in the scientific community. As more data become available, expression of lighting levels in terms of TLI will permit more relevant comparisons between studies of similar crops grown in different production scenarios.

\section{Conclusion}

Overall, the results of this study are demonstrative of how SS LI can affect the interplay between the most relevant factors of growth, yield, and quality for several economically important genotypes of Brassicaceae microgreens. Indoor growers of Brassicaceae microgreens can use these results, especially the light response curves for yield, to help determine the economic optimum LI to target for their production systems, genotypes, and production goals.

\section{Literature Cited}

Barrett, D.M., J.C. Beaulieu, and R. Shewfelt. 2010. Color, flavor, texture and nutritional quality of fresh-cut fruits and vegetables: Desirable levels, instrumental and sensory measurement, and the effects of processing. Crit. Rev. Food Sci. Nutr. 50:369-389.

Blom, T.J., M.J. Tsujita, and G.L. Roberts. 1995. Far-red at end of day and reduced irradiance affect plant height of Easter and Asiatic hybrid lilies. HortScience 30:1009-1012.

Bou-Torrent, J., G. Toledo-Ortiz, M. Ortiz-Alcaide, N. Cifuentes-Esquivel, K.J. Halliday, J.F. Martinez-Garcia, and M. Rodriguez-Concepcion. 2015. Regulation of carotenoid biosynthesis by shade relies on specific subsets of antagonistic transcription factors and cofactors. Plant Physiol. 169:1584-1594.

Burkholder, P.R. 1936. The rôle of light in the life of plants II. The influence of light upon growth and differentiation. Bot. Rev. 2:97-172.

Butler, R.D. 1963. The effect of light intensity on stem and leaf growth in broad bean seedlings. J. Expt. Bot. 14:142-152.

Craver, J.K., J.K. Boldt, and R.G. Lopez. 2019. Comparison of supplemental lighting provided by high-pressure sodium lamps or light- emitting diodes for the propagation and finishing of bedding plants in a commercial greenhouse. HortScience 54:52-59.

Craver, J.K., J.K. Boldt, and R.G. Lopez. 2018. Radiation intensity and quality from solesource light-emitting diodes affect seedling quality and subsequent flowering of long-day bedding plant species. HortScience 53:14071415.

Delgado, E., M.A.J. Parry, D.W. Lawlor, A.J. Keys, and H. Medrano. 1993. Photosynthesis, ribulose-1,5-bisphosphate carboxylase and leaf characteristics of Nicotiana tabacum L. genotypes selected by survival at low $\mathrm{CO}_{2}$ concentrations. J. Expt. Bot. 44:1-7.

Despommier, D. 2013. Farming up the city: The rise of urban vertical farms. Trends Biotechnol. 31:388-389.

Fletcher, J.M., A. Tatsiopoulou, M. Mpezamihigo, J.G. Carew, R.G.C. Henbest, and P. Hadley. 2005. Far-red light filtering by plastic film, greenhouse-cladding materials: Effects on growth and flowering in Petunia and Impatiens. J. Hort. Sci. Biotechnol. 80:303-306.

Gerovac, J.R., J.K. Craver, J.K. Boldt, and R.G. Lopez. 2016. Light intensity and quality from sole-source light-emitting diodes impact growth, morphology, and nutrient content of Brassica microgreens. HortScience 51:497503.

Givnish, T.J., R.A. Montgomery, and G. Goldstein 2004. Adaptive radiation of photosynthetic physiology in the Hawaiian lobeliads: Light regimes, static light responses and whole-plant compensation points. J. Amer. J. Bot. 91:228246

Hata, N., Y. Hayashi, E. Ono, H. Satake, A. Kobayashi, T. Muranaka, and A. Okazawa. 2013. Differences in plant growth and leaf sesamin content of the lignan-rich sesame variety 'Gomazou' under continuous light of different wavelengths. Plant Biotechnol. J. $30: 1-8$.

Hernández, R. and C. Kubota. 2014. Growth and morphological response of cucumber seedlings to supplemental red and blue photon flux ratios under varied solar daily light integrals. Scientia Hort. 173:92-99.

Hernández, R. and C. Kubota. 2016. Physiological responses of cucumber seedlings under different blue and red photon flux ratios using LEDs. Environ. Expt. Bot. 121:66-74.

Hisamatsu, T., K. Sumitomo, and H. Shimizu. 2008. End-of-day far-red treatment enhances responsiveness to gibberellins and promotes stem extension in chrysanthemum. J. Biotechnol. 83:695-700.

Karcher, D.E. and M.D. Richardson. 2003. Quantifying turfgrass color using digital image analysis. Crop Sci. 43:943-951.

Kim, E., S. Park, B. Park, Y. Lee, and M. Oh. 2014 Growth and antioxidant phenolic compounds in cherry tomato seedlings grown under monochromatic light-emitting diodes. Hort. Environ. Biotechnol. 5:506-513.

Kong, Y., K. Schiestel, and Y. Zheng. 2018. Pure blue light effects on growth and morphology are slightly changed by adding low-level UVA or far-red light: A comparison with red light in four microgreen species. J. Environ. Expt. Bot. 157:58-68.

Kozai, T. 2013. Plant factories in Japan-Current situation and prespectives. Chronica Hort. 53:8-11.

Krinsky, N.I. 1979. Carotenoid protection against oxidation. J. Pure. Appl. Chem. 51:649-660.

Krol, M., G.R. Gray, N.P.A. Huner, V.M. Hurry, G. Öquist, and L. Malek. 1995. Low-temperature stress and photoperiod affect an increased tolerance to photoinhibition in Pinus banksiana seedlings. Can. J. Bot. 73:1119-1127.

Kyriacou, M.C., Y. Rouphael, F. Di Gioia, A. Kyratzis, F. Serio, M. Renna, S. De Pascale, and P. Santamaria. 2016. Micro-scale vegetable production and the rise of microgreens. Trends Food Sci. Technol. 57:103-115.

Llewellyn, D. and Y. Zheng. 2018. Finetuning LEDs for a better light: How light spectrum makes a difference. Geenhouse Canada, Ontario. 15 June 2018. <https://www.green housecanada.com/>.

Llorente, B., J.F. Martinez-Garcia, C. Stange, and M. Rodriguez-Concepcion. 2017. Illuminating colors: Regulation of carotenoid biosynthesis and accumulation by light. Curr. Opin. Plant Biol. 37:49-55.

Mah, J.J., D. Llewellyn, and Y. Zheng. 2018. Morphology and flowering responses of four bedding plant species to a range of red to far red ratios. HortScience 53:472-478.

Mancinelli, A.L. 1983. The Photoregulation of Anthocyanin Synthesis, p. 640-661. In: W. Shropshire and H. Mohr (eds.). Photomorphogenesis. Encyclopedia of Plant Physiology (New Series), vol 16. Springer, Berlin, Heidelberg.

Marcelis, L.F.M., A.G.M. Broekhuijsen, E. Meinen, E.M.F.M. Nijs, and M.G.M. Raaphorst. 2006. Quantification of the growth response to light quantity of greenhouse grown crops. Acta Hort. 7:97-104.

Matos, F.S., R. Wolfgramm, P.C. Cavatte, F.G. Villela, M.C. Ventrella, and F.M. DaMatta. 2009. Phenotypic plasticity in response to light in the coffee tree. J. Environ. Expt. Bot. 67:421-427.

Mitchell, C. and G. Stutte. 2017. Sole-source lighting for controlled environment agriculture, p. 48-56. In: R. Lopez and E. Runkle (eds.). Light management in controlled environments. Meister Media, Middletown, DE

Morais, H., M.E. Medri, C.J. Marur, P.H. Caramori, A.M. Ribeiro, and J.C. Gomes. 2004. Modifications on leaf anatomy of Coffea arabica caused by shade of Pigeonpea (Cajanus cajan). Braz. Arch. Biol. Technol. J. 47:863-871.

Ouzounis, T., E. Rosenqvist, and C.O. Ottosen. 2015. Spectral effects of artificial light on plant physiology and secondary metabolism: A review. HortScience 50:1128-1135.

Poel, B.R. and E.S. Runkle. 2017. Seedling growth is similar under supplemental greenhouse lighting from high-pressure sodium lamps or lightemitting diodes. HortScience 52:388-394.

Potter, T.I., S.B. Rood, and K.P. Zanewich. 1999. Light intensity, gibberellin content and the resolution of shoot growth in Brassica. Planta 207:505-511.

Pramuk, L.A. and E.S. Runkle. 2005. Photosynthetic daily light integral during the seedling stage influences subsequent growth and flowering of Celosia, Impatiens, Salvia, Tagetes, and Viola. HortScience 40:1336-1339.

Randall, W.C. and R.G. Lopez. 2015. Comparison of bedding plant seedlings grown under solesource light-emitting diodes (LEDs) and greenhouse supplemental lighting from LEDs and high-pressure sodium lamps. HortScience 50:705-713.

Samuolienè, G., A. Brazaityte, J. Jankauskienè, A Viršile, R. Sirtautas, A. Novičkovas, S. Sakalauskiene, J. Sakalauskaite, and P. Duchovskis. 2013. LED irradiance level affects growth and nutritional quality of Brassica microgreens. Cent. Eur. J. Biol. 8:1241-1249. 
Sims, D.A. and R.W. Pearcy. 1994. Scaling sun and shade photosynthetic acclimation of Alocasia macrorrhiza (Araceae) to a transfer from low to high light. Amer. J. Bot. 79:449-455.

Singh, D., C. Basu, M. Meinhardt-Wollweber, and B. Roth. 2015. LEDs for energy efficient greenhouse lighting. Renew. Sustain. Energy Rev. 49:139-147.

Smillie, R.M. and S.E. Hetherington. 1999. Photoabatement by anthocyanin shields photosynthetic systems from light stress. Photosynthetica 36:451-463.

Tamulaitis, G., P. Duchovskis, Z. Bliznikas, K. Breivè, R. Ulinskaite, A. Brazaityte, A.
Novičkovas, and A. Žukauskas. 2005. Highpower light-emitting diode based facility for plant cultivation. J. Phys. D Appl. Phys. 38:3182-3187.

Toledo-Ortiz, G., E. Huq, and R. Concepcioìn. 2010. Direct regulation of phytoene synthase gene expression and carotenoid biosynthesis by phytochrome-interacting factors. Proc. Natl. Acad. Sci. USA 107:1162611631.

Treadwell, D.D., R. Hochmuth, L. Landrum, and W. Laughlin. 2016. Microgreens: A new specialty crop. Univ. Florida IFAS Ext. Bul. HS1164.
Xiao, Z., G.E. Lester, Y. Luo, and Q. Wang. 2012. Assessment of vitamin and carotenoid concentrations of emerging food products: Edible microgreens. J. Agr. Food Chem. 60:76447651.

Yeh, D.M. and P.Y. Hsu. 2004. Differential growth and photosynthetic response of selected cultivars of English ivy to irradiance. J. Hort. Sci. Biotechnol. 79:633-637.

Zervoudakis, G., G. Salahas, G. Kaspiris, and E. Konstantopoulou. 2012. Influence of light intensity on growth and physiological characteristics of common sage (Salvia officinalis L.). Braz. Arch. Biol. Technol. 55:89-95. 